\title{
Identifikasi Resiko Kegagalan Proses Penyebab Terjadinya Cacat Produk dengan Metode FMEA-SAW
}

\author{
Ari Basuki ${ }^{1 *}$, Ichdal Chusnayaini ${ }^{2}$ \\ Program Studi Teknik Industri, Fakultas Tenik, Universitas Trunojoyo Madura \\ Jl. Raya Telang, Kamal, Bangkalan 69162, Jawa Timur, Indonesia \\ aribasuki.utm@gmail.com ${ }^{1^{*}}$, naya.chusnaya11@gmail²
}

\section{INFO ARTIKEL}

Jejak Artikel :

Upload artikel

14 Oktober 2020

Revisi

14. September 2021

Publish

30 September 2021

\section{Kata Kunci :}

Kegagalan Proses, FMEA,

$S A W$, Cacat Produk
ABSTRAK

Tujuan dari penelitian ini yaitu melakukan identifkasi resiko terjadinya kegagalan proses yang berdampak pada terjadinya cacat produk di suatu perusahaan. Metode yang digunakan pada penelitian ini yaitu integrasi metode FMEA dengan metode SAW. Metode SAW digunakan untuk memberikan bobot pada faktor severity, occurance dan detection yang terdapat pada metode FMEA.Penelitian ini menggunakan studi kasus di PT. XYZ. PT. XYZ merupakan perusahaan manufaktur yang memproduksi kayu lapis (Plywood) dengan pasar ekspor. Berdasarkan data penelitian awal, diketahui perusahaan ini hanya mampu menghasilkan produk dengan kualitas ekspor sebesar 88,3\%, sisanya yaitu berupa produk kualitas lokal dan scrap. Oleh karena itu, dengan menggunakan metode FMEA-SAW ingin diketahui jenis kegagalan proses yang beresiko menyebabkan terjadinya produk cacat di PT.XYZ. Hasilnya yaitu bentuk kegagalan yang menempati prioritas tertinggi yaitu sebesar 25\% dari keseluruhan failure mode, yaitu kegagalan: hasil potongan genjang, bahan input terlalu lebar, hasil tidak dapat menyatu secara sempurna, lem terlalu encer, rusak fisik pada bahan, bahan tidak halus secara merata, veneer tebal tipis. 


\section{Pendahuluan}

Target dari suatu perusahaan yaitu bisa memberikan kepuasan konsumen dan bisa mendapatkan keuntungan sebesar-besarnya[1]. Ini bisa dicapai dengan cara memberikan layanan/produk yang kualitasnya sesuai dengan keinginan konsumen. Semakin tinggi tingkat kepuasan konsumen, maka bisa memberikan pengaruh bagi perusahaan untuk bisa mendapatkan profit yang semakin besar [2][3].

Kualitas hasil produksi dipengaruhi oleh berbagai faktor, diantaranya yaitu kualitas bahan baku [4] dan kondisi proses produksi [5]. Gangguan ataupun kegagalan yang terjadi dalam proses produksi dapat menyebabkan dampak negatif pada proses yang lainnya ataupun hasil produksi [6].

FMEA (Failure Mode and Effect Analysis) merupakan salah satu alat yang bisa digunakan untuk mengidentifikasi dan memberikan rekomendasi perbaikan gangguan yang terjadi pada proses produksi [7][8]. Berdasarkan hasil penelitian sebelumnya tentang implementasi FMEA, [9][10][11] menyatakan bahwa penggunaan metode ini pada bidang manufaktur mampu mengurangi terjadinya jumlah produk cacat [12].

Analisis FMEA dilakukan berdasarkan nilai Risk Priority Number (RPN). Nilai RPN merupakan suatu angka yang menyatakan tingkat prioritas resiko dari suatu kegagalan proses. Nilai resiko tersebut dihitung dari perkalian antara 3 komponen, yakni nilai Severity (S), Occurance (O) dan Detection (D) [13]. Masing-masing faktor tersebut memiliki bobot yang sama. Menurut Wu dkk.,[14] setiap faktor tersebut memiliki pengaruh yang berbeda terhadap besarnya resiko dari suatu kegagalan. Oleh karena itu dalam analisis FMEA, perhitungan nilai RPN akan lebih obyektif jika masing-masing faktor S, O, D dihitung terlebih dahulu bobotnya. Apakah setiap organisasi memberikan nilai bobot yang sama ataukah berbeda kepada setiap faktor tersebut.
Bobot (weight) suatu faktor dapat digunakan sebagai dasar untuk pengambilan keputusan [15]. Perhitungan bobot dapat dilakukan dengan berbagai macam metode, diantara AHP, ANP, SAW[16]. Masingmasing metode pembobotan memiliki kelebihan ataupun kekurangan. Diantara ketiga metode pembobotan tersebut, metode SAW (Simple Additive Weighting) merupakan metode pembobotan yang sederhana dalam perhitungannya dan penggunaannya, namun mampu memberikan hasil bobot yang baik[12].

Oleh karena itu, pada penelitian ini akan dikaji penggunaan metode FMEA yang akan diperbaiki dengan cara memberikan bobot pada setiap faktor S, O, D. Sebagai wujud implementasinya, maka pada penelitian ini akan digunakan studi kasus di PT.XYZ yang berupa identifikasi terjadinya kegagalan proses dilantai produksi PT.XYZ dengan tujuan untuk meminimalkan terjadinya produk cacat.

PT. XYZ merupakan perusahaan manufaktur yang memproduksi kayu lapis (plywood) dengan target pasar ekspor. Oleh karena itu, dalam proses produksinya dituntut untuk bisa menghasilkan produk dengan kualitas tinggi.

Berdasarkan hasil penelitian awal, diketahui bahwa terdapat beberapa gangguan yang masih terjadi pada proses produksinya. Beberapa gangguan tersebut menyebabkan terjadinya kegagalan proses yang berdampak pada kualitas hasil produksi.

Pada studi kasus penelitian ini yaitu PT. XYZ yang merupakan perusahaan penghasil Plywood dengan target pasarnya adalah ekspor. Proses pembuatan Plywood di perusahaan ini belum bisa menghasilkan kualitas produk yang seusai dengan harapan perusahaan. Berdasarkan data perusahaan selama 6 bulan (Juli-Desember 2019) diketahui bahwa perusahaan 'hanya' mampu menghasilkan produk dengan kualitas ekspor (G1) rata-rata sebesar $88,3 \%$, sisanya dikategorikan sebagai produk grade G2 $(3,3 \%)$ dan G3 $(5,5 \%)$ yang dijual di pasar lokal dan produk scrap sebanyak 2,9\%. Target 
perusahaan yaitu menghasilkan produk $100 \%$ grade G1. Terjadinya penurunan grade ini menyebabkan target keuntungan perusahaan tidak bisa tercapai secara maksimal.

Ketidaktercapaian target produksi ini disebabkan oleh berbagai faktor, salah satunya adalah terjadinya kegagalan proses yang terjadi di lantai produksi. Oleh karena itu, pada penelitian ini akan diidentifikasi berbagai resiko yang berpotensi menyebabkan terjadinya kegagalan proses dan pengaruhnya terhadap kualitas hasil produksi di PT. XYZ.

Penggunaan metode FMEA pada proses perhitungan nilai RPN menggunakan perkalian dari nilai S, O, D dengan bobot faktor S, O, D adalah sama. Sedangkan pada kenyataannya faktor-faktor tersebut bisa jadi oleh analis memiliki bobot yang tidak sama (berbeda). Oleh karena itu, pada penelitian ini dilakukan pembobotan dengan menggunakan metode SAW (Simple Additive Weighting) untuk mengetahui prioritas resiko kegagalan berdasarkan pembobotan yang ditentukan pada masing-masing faktor $\mathrm{S}, \mathrm{O}$, dan $\mathrm{D}$.

\section{Metode Penelitian}

Metode yang digunakan pada penelitian ini yaitu integrasi antara metode FMEA dan metode SAW. Metode FMEA digunakan untuk mendapatkan nilai RPN yang menyatakan tingkat resiko kegagalan proses. Dalam studi ini, nilai RPN tersebut menyatakan resiko kegagalan proses yang terjadi pada lantai produksi yang menyebabkan terjadinya kecacatan produk.

Nilai RPN dalam metode FMEA diperoleh dengan mengalikan faktor $\mathrm{S}, \mathrm{O}$, dan $\mathrm{D}$ dengan menggunakan formula berikut:

$R P N=S \times O \times D$

Dimana:

RPN : Risk Priority Number

$\mathrm{S} \quad$ : Severity

$\mathrm{O}$ : Occurance

D : Detection

Untuk mendapatkan nilai RPN yang terbobot, maka masing-masing faktor(S, O, D) akan ditentukan terlebih dahulu nilai bobot awalnya (Wi). Nilai ini diperoleh dari beberapa responden yang memahami tentang proses produksi dan hubungannya dengan kualitas produk yang dihasilkan oleh perusahaan tersebut.

Penilaian bobot tersebut dilakukan dengan cara memberikan kuisioner berskala 1-10. Masing-masing responden diminta untuk memberikan nilai bobot $\mathrm{S}, \mathrm{O}, \mathrm{D}$.

Hasil penilaian tersebut kemudian akan digabungkan menjadi sebuah nilai bobot awal (Wi) untuk setiap faktor S, O, dan D.

Nilai Wi ini kemudian akan digunakan dalam perhitungan nilai RPN terbobot dengan menggunakan metode SAW.

Perhitungan nilai bobot SAW dilakukan dengan tahapan sebagai berikut [17]:

1. Membuat matrik keputusan yang akan dinormalisasikan.

Hasil penilaian tingkat SOD untuk setiap jenis kegagalan proses disusun dalam bentuk matrik dengan ordo ( $\mathrm{m} \times \mathrm{n})$, dimana $m$ menyatakan banyaknya jenis kegagalan yang terjadi; dan $\mathrm{n}$ adalah nilai dari setiap faktor S, O, dan D.

2. Melakukan normalisasi matrik dengan menggunakan persamaan:

$$
r_{i j}=\frac{x_{i j}}{\max \left(x_{i j}\right)}
$$

Dimana:

$\mathrm{r}_{\mathrm{ij}}=$ matrik dinormalisasikan $[\mathrm{i}][\mathrm{j}]$

$\mathrm{x}_{\mathrm{ij}}=$ matrik keputusan [i][j]

$\mathrm{i}=1,2,3, \ldots, \mathrm{m}$

$\mathrm{j}=1,2,3, \ldots, \mathrm{n}$

$\max \mathrm{x}_{\mathrm{i}}=$ nilai tertinggi setiap kolom matrik.

Perhitungan normalisasi matriks dilakukan untuk memperoleh nilai normalisasi dari setiap nilai $\mathrm{S}, \mathrm{O}$, dan $\mathrm{D}$ pada setiap jenis failure mode.

3. Menghitung nilai akhir alternatif dengan menggunakan persamaan:

$$
v_{i j}=\sum_{j=1}^{n} w_{i} r_{i j}
$$

Dimana:

$\mathrm{Vij}=$ nilai akhir alternatif

$\mathrm{Wi}=$ nilai bobot

$\mathrm{r}_{\mathrm{ij}}=$ nilai yag dinormalisasikan

$\mathrm{n}=$ jumlah kriteria

Yang dimaksud dengan nilai akhir alternatif yaitu nilai relatif Risk Priority 
Index (RPI). Nilai RPI merefleksikan nilai RPN terbobot (nilai yang sudah diolah melalui proses pembobotan). Nilai ini diperoleh dengan menggunakan persamaan (3), yaitu dengan menjumlahkan setiap hasil perkalian bobot yang sudah ditentukan sebelumnya (Wi) dengan nilai hasil normalisasi matriks (langkah 2) setiap nilai $\mathrm{S}, \mathrm{O}$, dan D.

4. Merangking nilai akhir alternatif (RPI) secara descending (dari nilai terbesar ke nilai tekecil). Nilai terbesar menunjukkan jenis kegagalan proses paling beresiko sebagai penyebab utama terjadinya cacat produk.

\section{Hasil dan Pembahasan}

Berdasarkan hasil pengamatan di lantai produksi PT.XYZ, diketahui terdapat 28 jenis kegagalan proses yang pernah terjadi dalam kurun waktu 6 bulan (2019). Ke 28 bentuk kegagalan tersebut berakibat terjadinya berbagai macam bentuk kecacatan produk. Hasil FMEA dari penilaian faktor S, O, D untuk setiap jenis kegagalan tersebut ditunjukkan pada tabel 1.

Tabel 1. Hasil penilaian aspek Severity (S), Occurance (O) dan Detection (D) di PT.XYZ

\begin{tabular}{|c|c|c|c|c|c|c|c|}
\hline $\begin{array}{l}\text { Proses (Work } \\
\text { Station) }\end{array}$ & Failure Mode & Kode & Effect & $\mathrm{S}$ & $\mathrm{O}$ & $\mathrm{D}$ & RPN \\
\hline \multirow[b]{2}{*}{ Rotary } & veneer tebal tipis & $\mathrm{F} 1$ & terjadi uneven thickness dan rawan delaminasi & 9 & 2 & 1 & 18 \\
\hline & veneer berjamur & $\mathrm{F} 2$ & $\begin{array}{l}\text { pori-pori veneer tertutup sehingga lem susah } \\
\text { masuk }\end{array}$ & 4 & 2 & 3 & 24 \\
\hline \multirow{2}{*}{$\begin{array}{l}\text { Hot press } \\
\text { veneer }\end{array}$} & $\begin{array}{l}\text { veneer tumpang tindih ketika } \\
\text { dipress }\end{array}$ & $\mathrm{F} 3$ & thickness plywood \& kerataan lem saat di proses & 3 & 2 & 2 & 12 \\
\hline & $\begin{array}{l}\text { kering veneer tidak merata } \\
\text { (spot } \mathrm{mc})\end{array}$ & $\mathrm{F} 4$ & lem tidak dapat melekat secara sempurna & 4 & 2 & 2 & 16 \\
\hline \multirow{2}{*}{ Core Builder } & bahan input terlalu lebar & F5 & bahan tidak dapat masuk/diproses oleh mesin & 9 & 2 & 2 & 36 \\
\hline & temperatur bahan panas & F6 & benang tidak menempel secara maksimal & 2 & 2 & 1 & 4 \\
\hline \multirow{2}{*}{ Scraf } & hasil amplas terlalu tipis & F7 & terdapat cekungan pada sambungan & 3 & 3 & 3 & 27 \\
\hline & benang putus-putus & F8 & bahan ada yang teramplas dan tidak & 4 & 4 & 3 & 48 \\
\hline \multirow{2}{*}{$\begin{array}{l}\text { Scraf Veneer } \\
\text { Composer }\end{array}$} & Lem M.A 204 lawas & F9 & sambungan veneer tidak lengket secara maksimal & 4 & 4 & 3 & 48 \\
\hline & $\begin{array}{l}\text { Hasil tidak dapat menyatu } \\
\text { sempurna }\end{array}$ & F10 & bahan tidak terpakai dan menjadi reject & 9 & 2 & 2 & 36 \\
\hline \multirow{2}{*}{ Repair } & terdapat bahan mc tinggi & F11 & menyebabkan plywood delaminasi & 4 & 2 & 3 & 24 \\
\hline & terdapat bahan uneven thickness & F12 & menyebabkan lem tidak rata saat di GS & 4 & 2 & 3 & 24 \\
\hline \multirow[b]{2}{*}{ Shikumi } & benang CB terbalik saat setting & F13 & menyulitkan operator GS & 3 & 1 & 3 & 9 \\
\hline & $\begin{array}{l}\text { sisa-sisa benang/sampah tidak } \\
\text { dibuang }\end{array}$ & F14 & lem banyak terbuang & 4 & 2 & 2 & 16 \\
\hline \multirow{3}{*}{$\begin{array}{l}\text { Glue } \\
\text { Speader }\end{array}$} & bahan tidak siku & F15 & $\begin{array}{l}\text { ukuran kurang panjang setelah dipotong double } \\
\text { saw }\end{array}$ & 4 & 2 & 2 & 16 \\
\hline & MC tinggi & F16 & veneer tidak menempel secara sempurna & 3 & 2 & 3 & 18 \\
\hline & Suhu tinggi & F17 & terjadi precure sebelum masuk hot press & 3 & 2 & 3 & 18 \\
\hline \multirow{2}{*}{ Mixer } & lem terlalu encer & F18 & menyebabkan delaminasi dan pre bonding jelek & 9 & 2 & 2 & 36 \\
\hline & waktu mixer kurang & F19 & viskositas lem rendah, daya rekat berkurang & 4 & 2 & 2 & 16 \\
\hline Cold press & Tatanan bahan tidak rata/miring & F20 & pre bonding kurang baik & 3 & 3 & 2 & 18 \\
\hline \multirow{2}{*}{$\begin{array}{l}\text { Hot Press } \\
\text { Plywood }\end{array}$} & Bahan output delaminasi & F21 & bahan down grade & 8 & 2 & 1 & 16 \\
\hline & Rusak fisik pada bahan & F22 & bahan output harus diperbaiki ulang & 9 & 2 & 2 & 36 \\
\hline \multirow{2}{*}{ Double Saw } & hasil potongan hitam & F23 & grade kurang bagus & 3 & 2 & 2 & 12 \\
\hline & hasil potongan genjang & F24 & bahan down grade & 9 & 2 & 3 & 54 \\
\hline Putty 1 & dempul susut & $\mathrm{F} 25$ & permukaan bahan tidak rata & 4 & 2 & 3 & 24 \\
\hline $\begin{array}{l}\text { Sander } \\
\text { Calibration }\end{array}$ & bahan tidak halus secara merata & F26 & bahan down grade & 4 & 1 & 1 & 4 \\
\hline Putty 2 & putty smir & F27 & bahan down grade & 4 & 2 & 2 & 16 \\
\hline $\begin{array}{l}\text { Sander } \\
\text { Finish }\end{array}$ & bahan tidak halus secara merata & F28 & bahan down grade & 8 & 2 & 2 & 32 \\
\hline
\end{tabular}

Sumber: Hasil Pengolahan Data 2019 
Penilaian bobot awal (Wi) untuk setiap faktor S, O, D diperoleh dari pihak owner, manajer produksi, manajer QC, staff produksi, dan staff QC, dan setelah digabungkan menghasilkan nilai masing-masing sebesar 0,$518 ; 0,272 ; 0,210$.

Dari nilai tersebut dapat dikatakan bahwa pihak perusahaan menilai aspek tingkat kegawatan atau keparahan (severity) yang dihasilkan dari kegagalan proses dinilai lebih signifikan (dengan bobot nilai 0,518) berhubungan dengan terjadinya cacat produk jika dibandingkan dengan aspek occurance (frekuensi terjadinya kegagalan proses dengan bobot 0,0272)maupun aspek detection yang artinya kemampuan sistem dalam mendeteksi terjadinya suatu kegagalan proses (dengan bobot 0,210).

Hasil penilaian S, O, D setiap jenis kegagalan dijadikan sebagai sebuah matriks yang berordo $28 \times 3$. Terdapat 28 jenis kegagalan proses (sebagai baris dalam matrik) dan 3 aspek yaitu S, O, D (sebagai kolom dalam matriks).

Matrik ini kemudian dinormalisasikan dengan cara mengalikan bobot Wi dengan matrik (Pers. 2) Sebagai contoh perhitungan yaitu untuk memperoleh nilai normalisasi matriks dari failure mode F1 (veener tebal tipis), dihitung dengan cara sebagai berikut:

$$
\begin{aligned}
\mathrm{r}_{11} & =\frac{9}{\max (9 ; 4 ; 3 ; 4 ; 9 ; 2 ; 3 ; 4 ; 4 ; 9 ; 4 ; 4 ; 3 ; 4 ; 4 ; 3 ; 3 ; 9 ; 4 ; 3 ; 8 ; 9 ; 3 ; 9 ; 4 ; 4 ; 4 ; 8)} \\
& =1 \\
\mathrm{r}_{12} & =\frac{2}{\max (2 ; 2 ; 2 ; 2 ; 2 ; 2 ; 3 ; 4 ; 4 ; 2 ; 2 ; 2 ; 1 ; 2 ; 2 ; 2 ; 2 ; 2 ; 2 ; 3 ; 2 ; 2 ; 2 ; 2 ; 2 ; 1 ; 2 ; 2)} \\
& =0,5 \\
\mathrm{r}_{13} & =\frac{1}{\max (1 ; 3 ; 2 ; 2 ; 2 ; 1 ; 3 ; 3 ; 3 ; 2 ; 3 ; 3 ; 3 ; 2 ; 2 ; 3 ; 3 ; 2 ; 2 ; 2 ; 1 ; 2 ; 2 ; 3 ; 3 ; 1 ; 2 ; 2)} \\
& =0,333
\end{aligned}
$$

Perhitungan ini dilakukan untuk semua jenis failure.

Selanjutnya yaitu mendapatkan nilai Risk Priority Index (RPI) dengan menggunakan persamaan 3. Sebagai contoh perhitungan yaitu:

$$
\begin{aligned}
\mathrm{v}_{11} & =0,518 \times 1 \\
& =0,518 \\
\mathrm{v}_{12} & =0,272 \times 0,5 \\
& =0,136 \\
\mathrm{v}_{13} & =0,210 \times 0,333 \\
& =0,07
\end{aligned}
$$

Jadi, nilai RPI $\left(\mathrm{V}_{\mathrm{ij}}\right)=0,518+0,136+0,07=$ 0,724
Perhitungan tersebut dilakukan hingga diperoleh nilai setiap $\mathrm{V}_{\mathrm{ij}}$ dan dilakukan perangkingan. Hasil perhitungan lengkapnya ditunjukkan pada tabel 2 berikut.

Tabel 2.Nilai RPI dan Rangkingnya

\begin{tabular}{|c|c|c|}
\hline Kode & RPI & Ranking \\
\hline F1 & 0.724 & 7 \\
\hline F2 & 0.576 & 12 \\
\hline F3 & 0.449 & 25 \\
\hline F4 & 0.506 & 19 \\
\hline F5 & 0.794 & 2 \\
\hline F6 & 0.321 & 28 \\
\hline F7 & 0.587 & 11 \\
\hline F8 & 0.712 & 8 \\
\hline F9 & 0.712 & 8 \\
\hline F10 & 0.794 & 2 \\
\hline F11 & 0.576 & 12 \\
\hline F12 & 0.576 & 12 \\
\hline F13 & 0.451 & 24 \\
\hline F14 & 0.506 & 19 \\
\hline F15 & 0.506 & 19 \\
\hline F16 & 0.519 & 16 \\
\hline F17 & 0.519 & 16 \\
\hline F18 & 0.794 & 2 \\
\hline F19 & 0.506 & 19 \\
\hline F20 & 0.517 & 18 \\
\hline F21 & 0.666 & 10 \\
\hline F22 & 0.794 & 2 \\
\hline F23 & 0.449 & 25 \\
\hline F24 & 0.864 & 1 \\
\hline F25 & 0.576 & 12 \\
\hline F26 & 0.368 & 27 \\
\hline F27 & 0.56 & \\
\hline F28 & 0.5 & 19 \\
\hline & 0.5 & 2 \\
\hline
\end{tabular}

Apabila dilihat perbandingan nilai priority risk pada tabel 1 dan tabel 2, maka terlihat adanya perbedaan nilai dan urutan ranking. Meskipun demikian, perbedaan ranking tersebut tidak jauh.

Oleh pihak perusahaan, penggunaan pendekatan FMEA-SAW menurutnya dinilai lebih mendekati kondisi riil yang dialami oleh perusahaan. Menurut pihak perusahaan, salah satu kejadian resiko yang selama ini paling 
sering dialami pada proses produksi yaitu pada komponen bahan baku, diantaranya yaitu bahan baku terdowngrade, bahan baku tidak bisa diproses oleh mesin (tidak dapat masuk ke mesin), bahan baku tidak bisa dipakai dan menjadi bahan reject. Kejadian resiko ini, apabila dinilai dengan metode FMEA, hasilnya tidak berada pada tingkatan resiko yang sering terjadi (bukan pada peringkat teratas dengan nilai RPN tinggi). Akan tetapi, jika resikoresiko tersebut dinilai dengan menggunakan metode FMEA-SAW, maka nilainya berada pada peringkat teratas. Oleh karena itu dapat dikatakan bahwa pendekatan FMEA-SAW bisa digunakan sebagai alternatif penilaian prioritas terjadinya resiko dari suatu kegagalan.

Jadi, pada tabel 2 nilai RPIini bisa digunakan sebagai pengganti nilai RPN yang menyatakan tingkat prioritas resiko dari suatu failure mode. Semakin besar nilai RPI atau RPN, maka resiko dari suatu kegagalan menjadi semakin kritis dan segera membutuhkan tindakan perbaikan.

\section{Usulan Perbaikan Jenis Kegagalan}

Nilai RPI di tabel 2 dijadikan sebagai bahan diskusi dengan pihak perusahaan untuk menentukan berbagai rekomendasi yang bisa meminimalkan terjadinya cacat produk. Hasil diskusi dengan pihak perusahaan, perusahaan menyatakan bahwa upaya solusi bentuk kegagalan yang menempati prioritas tertinggi yaitu sebesar $25 \%$ dari keseluruhan failure mode. Sehingga dipilih ranking 1 sampai dengan 7 untuk dilanjutkan pada tahap usulan perbaikan. Hasilnya yaitu:

1. Usulan terhadap bentuk kegagalan hasil potongan genjang. Melakukan pengecekan secara berkala terhadap pelatuk pada mesin. Pengecekan dilakukan baik sebelum mesin beroperasi maupun ketika mesin sedang beroperasi. Kemudian operator sebaiknya memperhatikan dan memeriksa feeding roll sebelum mesin digunakan sekaligus pada saat mesin beroperasi. Hal tersebut bertujuan agar apabila terdapat sampah yang tertinggal pada feeding roll dapat dibersihkan terlebih dahulu sehingga hasil potongan sesuai dengan ukuran dan tidak genjang.

2. Usulan terhadap bentuk kegagalan bahan input terlalu lebar. Operator workstation core builder harus memastikan bahan input yang masuk ke workstation core builder memiliki ukuran yang sesuai dengan standar sehingga dipastikan dapat diproses pada mesin core builder.

3. Usulan terhadap bentuk kegagalan hasil tidak dapat menyatu secara sempurna.Operator lebih memperhatikan dan memeriksa mesin press sebelum mesin digunakan sekaligus pada saat mesin beroperasi. Hal tersebut bertujuan agar apabila terdapat sampah yang tertinggal dapat dibersihkan terlebih dahulu sehingga hasil press bisa merekat secara sempurna dan menghindari hasil veneer yang tidak menyatu. Pengecekan bisa dilakukan pula secara rutin agar mesin selalu dalam keadaan bersih.

4. Usulan terhadap bentuk kegagalan lem terlalu encer. Untuk meminimalisir kesalahan, maka operator bisa membuat petunjuk pencampuran lem beserta komposisinya di dekat tempat pencampuran lem, sehingga dapat dijadikan sebagai panduan dalam proses pencampuran lem.

5. Usulan terhadap bentuk kegagalan rusak fisik pada bahan. Sebaiknya lebih teliti dan hati-hati saat memasukkan bahan ke dalam hot press plywood. Karena apabila posisi bahan tidak tepat pada tempatnya, maka pada saat mesin press berfungsi, bahan tertekan dengan posisi salah sehingga mengakibatkan bahan terlipat atau bahkan sobek.

6. Usulan terhadap bentuk kegagalan bahan tidak halus secara merata. Memastikan bahan yang masuk ke workstation finishing sander memiliki ketebalan yang sama, sehingga ketika dilakukan pengamplasan yang terakhir sebelum dilakukan grading maka dapat menghasilkan plywood dengan ketebalan yang sama.

7. Usulan terhadap bentuk kegagalan veneer tebal tipis. Setting pisau pada mesin speandless harus sesuai dengan ketebalan yang diinginkan sebelum mesin digunakan. Kemudian, melakukan penggantian mata pisau secara rutin agar pisau terjaga ketajamannya dan dapat meminimalisir hasil peeling yang memiliki ketebalan tidak rata (tebal tipis).

\section{Kesimpulan dan Saran}

\begin{tabular}{|c|c|}
\hline $\begin{array}{l}\text { Metode } \\
\text { sebagai }\end{array}$ & $\begin{array}{l}\text { FMEA-SAW dapat } \\
\text { metode alternatif }\end{array}$ \\
\hline
\end{tabular}


proses beserta dampaknya. Dengan mengitegrasikan metode SAW ke metode FMEA, maka faktor S, O, D yang merupakan faktor penentu besarnya prioritas resiko akan dinilai dengan lebih obyektif dengan cara memberikan bobot pada setiap faktor $\mathrm{S}, \mathrm{O}$, dan D. Dengan adanya bobot ini , maka perusahaan bisa menyesuaikan tingkat kepentingan pengaruh $\mathrm{S}$, O, D terhadap potensi resiko terjadinya kegagalan. Hal ini tidak bisa dilakukan jika menggunakan metode FMEA konvensional, karena faktor S, O, D -nya akan diberi nilai bobot yang sama.

Hasil dari perhitungan FMEA-SAW pada studi kasus di PT.XYZ menunjukkan bahwa terdapat sedikit perbedaan hasil dengan perhitungan FMEA. Menurut pihak perusahaan, hasil FMEA-SAW lebih mendekati kondisi riil yang dihadapi perusahaan. Jika di rangking berdasarkan tujuh bentuk kegagalan dengan prioritas resiko terbesar, hasilnya yaitu bentuk kegagalan hasil potongan genjang menempati posisi teratas sebagai penyebab terjadinya cacat produk, kemudian diikuti dengan bentuk kegagalan bahan input terlalu lebar, kegagalan hasil tidak dapat menyatu secara sempurna, bentuk kegagalan lem terlalu encer, bentuk kegagalan rusak fisik pada bahan, kegagalan bahan tidak halus secara merata, bentuk kegagalan veneer tebal tipis.

Pihak perusahaan disarankan supaya melakukan pengecekan secara berkala terhadap pelatuk pada mesin. Kemudian operator sebaiknya memperhatikan dan memeriksa feeding roll sebelum mesin digunakan sekaligus pada saat mesin beroperasi sebagai upaya untuk mengurangi terjadinya down grade atau banyaknya produk cacat.

Bagi penelitian selanjutnya, bisa dikaji efektifitas penggunaan metode FMEA dengan metode pembobotan yang lain, seperti AHP, ANP ataupun dengan mengintegrasikan metode perankingan seperti TOPSIS atau metode lainnya.

\section{Daftar Pustaka}

[1] Hallowell, R. "The relationships of customer satisfaction, customer loyalty, and profitability: an empirical study". International journal of service industry management, 1996.
[2] Zhang, C., \& Pan, F. "The impacts of customer satisfaction on profitability: a study of state-owned enterprises in China". Service Science, 1(1), 22-30, 2009.

[3] Khadka, K., \& Maharjan, S. "Customer satisfaction and customer loyalty". Centria University of Applied Sciences, Business Management, 2017.

[4] Salim, R., \& Johansson, J. "The influence of raw material on the wood product manufacturing". Procedia CIRP, 57, 764768, 2016.

[5] Afolabi, A., Johnson, O. T., \& Abdulkareem, A. S. "The Effect of Raw Materials and Production Conditions on Glass Quality". In Proceedings of the World Congress on Engineering (Vol. 3, pp. 1-3), 2012.

[6] Ahmad, S., Badwelan, A., Ghaleb, A. M., Qamhan, A., Sharaf, M., Alatefi, M., \& Moohialdin, A. "Analyzing critical failures in a production process: Is industrial IoT the solution?". Wireless Communications and Mobile Computing, 2018.

[7] Görener, A., \& Toker, K. "Quality Improvement in Manufacturing Processes to Defective Products using Pareto Analysis and FMEA". Beykent University Journal of Social Sciences-BUJSS, 6(2), 2013.

[8] Tsai, S. B., Zhou, J., Gao, Y., Wang, J., Li, G., Zheng, Y., ... \& Xu, W. "Combining FMEA with DEMATEL models to solve production process problems". Plos One, 12(8), e0183634, 2017.

[9] Roesmasari, R. A., Santoso, I. \& S., "Strategi Peningkatan Kualitas Leather Dengan Metode Lean Six Sigma Dan Fuzzy FMEA (Studi Kasus Di Sumber Rejeki)". Jurnal Teknologi Pertanian, Volume 19 No. 3, pp. 183-192, 2018.

[10] Hanif, R. Y., Rukmi, H. S., \& Susanty, S. "Perbaikan kualitas produk keraton luxury di PT. X dengan menggunakan metode failure mode and effect analysis (FMEA) dan FAULT TREE ANALYSIS (FTA)". Reka Integra, 3(3), 2015.

[11] Dudek-Burlikowska, M. "Application of FMEA method in enterprise focused on quality". Journal of achievements in 
Materials and Manufacturing Engineering, 45(1), 89-102, 2011.

[12] Suwandi, A., Zagloel, T. Y., \& Hidayatno, A. "Minimization of Pipe Production Defects using the FMEA method and Dynamic System". International Journal of Engineering Research and Technology, 13(5), 953-961, 2020.

[13] Agusta, R. D. “Analisis Kecelakaan Kerja Pada Pekerjaan Pembersihan ESP Di Departement Oleo Chemical Dengan Menggunakan Metode Failure Mode And Effect Analysis (FMEA) Dan Root Cause Analysis (RCA) Study kasus: PT. Wilmar Nabati Indonesia". (Doctoral dissertation, Universitas Muhammadiyah Gresik, 2014).

[14] Wu, J., Tian, J., \& Zhao, T. "Failure mode prioritization by improved RPN calculation method. In 2014 Reliability and Maintainability Symposium (pp. 1-6), 2014, IEEE.

[15] Shanteau, J. "The Concept of Weight in Judgment and Decision Making: A Review and Some Unifying Proposals (No. CRJP-228)". Colorado Univ At Boulder Center For Research On Judgment And Policy, 1980.

[16] Velasquez, M., \& Hester, P. T. "An analysis of multi-criteria decision making methods". International journal of operations research, 10(2), 56-66, 2013.

[17] Afshari, A., Mojahed, M., \& Yusuff, R. M. "Simple additive weighting approach to personnel selection problem". International Journal of Innovation, Management and Technology, 1(5), 511, 2010. 